\title{
WIRELESS TELEGRAPHY IN THE SERVICE OF JAPANESE METEOROLOGY.
}

It is hardly necessary to say that wireless weather reports from vessels at sea would be of great service to practical meteorology in Japan. As many of the most destructive storms come on us from the Pacific ocean, a daily knowledge of the weather conditions prevailing out at sea could not fail to be of a great value to us. It also must be of great benefits to the captains at sea far off from land to receive storm warnings from the Central Meteorological Observatory.

The first attempts to utilize wireless telegraphy for the benefit of the we ather service were undertaken in August of 1904 by the London Daily Telegraph, and the United States Weather Bureau,. also, made use some years ago of such reports from vessels on the Atlantic. In this country the first wireless weather reports were made for some time in $19 c 6$ betwreen the temporarily established naval sem aphore on Hachijojima and the Central Meteorological Observatory, but this was soon brought to a standstill. The present system of wireless weather reports has been carried into effect from May of 19I0. The following is the abstract of the code of meteorological wireless telegrams in Japan.

I. Meteorological telegrams. - A vessel passing within range 
of correspondence of any wireless telegraphic coast station is requested to communicate meteorological observations taken at $6 \mathrm{am}, 2 \mathrm{pm}$ and $10 \mathrm{pm}$ to the Central Meteorological Observatory, Tokyo. In threatening weather extra observations at any hour is to be despatched besides the regular ones. The meteorological telegram consists of 18 ciphers, and contains date, hour, the position of the ship, height of the barometer, wind direction and force, weather, and the state of sea. The position of the ship is given by the longitude and latitude. The barometer reading is reported in inches and hundredths or in millimetres and tenths. Direction of the wind is given in sixteen points of compass and the force is estimated according to the Beaufort scalc. The weather is reported according to the following notation:
o. Clear.
2. Cloudy.
4. Snow.
6. Thunderstorm.
I. Fair.
3. Rain.
5. Fog.
7. Haze.

The state of sea is estimated according to the following seven grades.
o. Dead calm. 2. Swell. 4. Moderate. 6. Very high.
I. Smooth. 3. Slight. 5. Rough. 7. Tremendous,

II. Indication.-when a typhoon or a cyclonic centre of dangerous intensity appeared the Central Meteorological Observatory despatches warning telegrams to vessels at sea through 
wireless telegraphic coast stations. The indication telegram: consists of 15 ciphers and contains indication, date, hour, the position and depth of the centre, and direction of motion. Indication announces a depression or a typhoon. The position of the centre is given by the longitude and latitude, and the depth is reported in inches. Direction of the progressive motion of the centre is reported according to the subjoined notation.

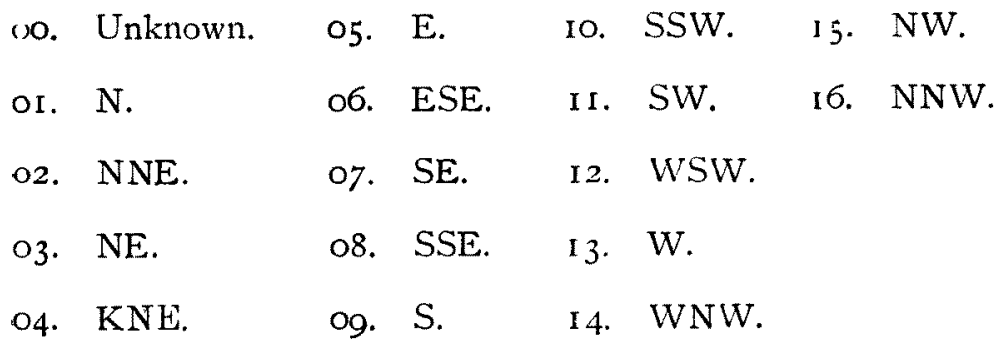

The specimens of these telegrams are given below.

I. Meteorological telegram-

$$
\begin{array}{lllllllll}
\text { I } 5 & 06 & 145 & 37 & 2892 & 02 & 08 & \text { I } & 5
\end{array}
$$

Translation. Date: the i 5 th.

Hour : 6am.

Position: $145^{\circ} \mathrm{E}$ and $37^{\circ} \mathrm{N}$.

Barometer : 28.92 inches.

Wind dir: NNE.

Wind force: Fresh gale.

Weather: Fair. 
Sea disturbance: Rough.

2. Indication telegram-

$\begin{array}{lllllll}2 & 21 & 14 & 136 & 31 & 2784 & 03\end{array}$

Translation. A typhoon is lying.

Date: the 2 Ist.

Hour : $2 \mathrm{pm}$.

Pusition of the centre: $136^{\prime} \mathrm{E}$ and $31^{\circ} \mathrm{N}$.

Depth : 27.84 inches.

Direction of motion : NE.

Next I will give below the positions of the wireless telegraphic coast stations.

Name.

N. Latitude.

E. Longitude.

Choshi. $35^{\circ} 44^{\prime}$ $140^{\circ} 50^{\circ}$

Shiomisaki.

3326

13546

Tsunoshima.

342 I

13050

Osesaki.

3237

12836

Ochiishi.

439

$14 ; 30$

When a vessel arrived at Yokohama or is to leave the port, the barometer in use on board is minutely examined and compared by the chief of the Yokohama Observatory with the standard barometer of the.Yokohama Meteorological Observatory, and the instrumental correction thereby obtained is immediately reported 
by post to the Central Meteorological Observatory.

All steamers equipped with wireless telegraphic apparatus communicate meteorological observations to the Central Meteorological Observatory. Among these the principal ones are those of the Nippon Yusen Kaisha and the T.oyo Kisen Kaisha, and also His Majesty's Ships. These telegrams come even from a distance as far off as $180^{\circ}$ east longitude. The vessels which forwarded the reports during last year were as follows :

S. S. Chiyo, Tenyo, Nippon, Hongkong, Awa, Shinano, Kamakura, Tanba, Inaba, Kayo, Sado, Taisei, Sanuki, America and His Majesty's Ships.

Japan has frequent visitations of typhoons every year, and those which originate in the Pacific are cyclonic storms of most dangerous intensity. Unfortunately our insular and exposed position has precluded any early knowledge of the advent of cyclones. Now, however, it has, to a certain extent, been remedied by the employment of the wireless telegraph. Accordingly it can hardly be doubted that satisfactory progress would be made in the knowledge of the laws of our storms and our weather. 